\title{
UHRF1 is a genome caretaker that facilitates the DNA damage response to $\gamma$-irradiation
}

\author{
Helena Mistry ${ }^{1 \dagger}$, Laura Tamblyn ${ }^{1 \dagger}$, Hussein Butt ${ }^{1}$, Daniel Sisgoreo ${ }^{1}$, Aileen Gracias ${ }^{1}$, Meghan Larin ${ }^{1}$, \\ Kalpana Gopalakrishnan², Manoor Prakash Hande², John Peter McPherson ${ }^{1 *}$
}

\begin{abstract}
Background: DNA double-strand breaks (DSBs) caused by ionizing radiation or by the stalling of DNA replication forks are among the most deleterious forms of DNA damage. The ability of cells to recognize and repair DSBs requires post-translational modifications to histones and other proteins that facilitate access to lesions in compacted chromatin, however our understanding of these processes remains incomplete. UHRF1 is an E3 ubiquitin ligase that has previously been linked to events that regulate chromatin remodeling and epigenetic maintenance. Previous studies have demonstrated that loss of UHRF1 increases the sensitivity of cells to DNA damage however the role of UHRF1 in this response is unclear.

Results: We demonstrate that UHRF1 plays a critical role for facilitating the response to DSB damage caused by $\gamma$ irradiation. UHRF1-depleted cells exhibit increased sensitivity to $\gamma$-irradiation, suggesting a compromised cellular response to DSBs. UHRF1-depleted cells show impaired cell cycle arrest and an impaired accumulation of histone $\mathrm{H} 2 \mathrm{AX}$ phosphorylation $(\gamma \mathrm{H} 2 \mathrm{AX})$ in response to $\gamma$-irradiation compared to control cells. We also demonstrate that UHRF1 is required for genome integrity, in that UHRF1-depleted cells displayed an increased frequency of chromosomal aberrations compared to control cells.
\end{abstract}

Conclusions: Our findings indicate a critical role for UHRF1 in maintenance of chromosome integrity and an optimal response to DSB damage.

\section{Background}

UHRF1 (also known as Np95 and ICBP90) was originally identified as a protein whose subcellular expression pattern coincided with sites of DNA replication [1-3]. Further studies supported a role for this protein in $S$ phase progression, particularly in replication of heterochromatin regions surrounding centromeres known as pericentric heterochromatin [4-6]. This role in heterochromatin replication and maintenance is linked to the ability of UHRF1 to facilitate several epigenetic modifications of histones and DNA [5-7]. UHRF1 binds to and ubiquitinates histone $\mathrm{H} 3[7,8]$ and facilitates deacetylation of lysine 8,12 , and 16 of heterochromatin histone H4 [6,9]. The SET and RING associated (SRA) domain of UHRF1 binds to hemi-methylated DNA and plays a crucial role in copying pre-existing methylation patterns

\footnotetext{
* Correspondence: peter.mcpherson@utoronto.ca

† Contributed equally

${ }^{1}$ Department of Pharmacology and Toxicology, University of Toronto, Toronto, Ontario, M5 S 1A8, Canada
}

onto newly replicated DNA by recruiting the DNA methyltransferase Dnmt1 to replication sites [10-14]. In addition to its function in duplicating DNA methylation patterns, UHRF1 binds to histone $\mathrm{H} 3$ tri-methylated at lysine 9 (H3K9me3) and plays a role in maintaining this histone modification in heterochromatin [7]. A recent study has pointed to the importance of a tandem tudor domain for UHRF1 binding to H3K9me3 [15].

Several studies have now identified a role for UHRF1 in the maintenance of heterochromatin modifications independent of its role in DNA replication. UHRF1 acts to facilitate promoter silencing $[9,16-19]$. This ability to repress transcription has been linked to UHRF1's recruitment of G9a histone methyltransferase and DNA methyltransferases Dnmt3a/b that repress transcription in euchromatin through the dimethylation of $\mathrm{H} 3 \mathrm{~K} 9$ and DNA methylation respectively $[17,18]$.

Previous studies have demonstrated a critical role for UHRF1 in the cellular response to a wide range of stimuli that result in DNA damage. Murine embryonic

\section{() Biomed Central}


stem cells with a targeted disruption in Uhrf1 are more sensitive to $\mathrm{x}$-rays, UV light, base damaging agents and hydroxyurea than wild-type cells [20]. Ablation of human UHRF1 results in hypersensitivity to X-rays, UV light and hydroxyurea [21]. Despite these observations, the mechanism whereby UHRF1 confers a protective role to various genotoxic stresses remains unclear. In this study, we identify a novel role for this protein as a genome caretaker and demonstrate that the hypersensitivity of UHRF1-depleted cells to irradiation can be attributed to an impaired ability to mount an optimal DNA damage response.

\section{Materials and methods Cell lines}

Human HeLa cells (ATCC) with diminished expression of UHRF1 were selected for resistance to puromycin following stable transfection with either $\mathrm{HuSH} 29$ mer short hairpin RNA (shRNA) constructs against UHRF1 (5'-AGG AGA CGT TCC AGT GTA TCT GCT GTC AG-3' and '5-TTC GTG GAC GAA GTC TTC AAG ATT GAG CG-3') or with a control shRNA plasmid (pRS-shGFP, non-effective, Origene), together with a vector conferring puromycin resistance. Three cloned cell lines expressing UHRF1 shRNA that demonstrated decreased levels of UHRF1, together with three cell lines transfected with control vector were selected for further analysis. Growth of individual cell lines was monitored by seeding cells at $3.5 \times 10^{5} /$ dish in triplicate and counting cell numbers using a hemacytometer at three day intervals. Growth curves show the cumulative mean cell number \pm standard deviation of five counts.

\section{Western blotting}

For Western analysis, cells were lysed in RIPA buffer (50 $\mathrm{mM}$ Tris- $\mathrm{HCl} \mathrm{pH}$ 8.0, $150 \mathrm{mM} \mathrm{NaCl}, 1 \mathrm{mM}$ PMSF, 1 mM EDTA, 1\% Triton X-100, 1\% sodium deoxycholate, $0.1 \% \mathrm{SDS}, 5 \mu \mathrm{g} / \mathrm{ml}$ aprotinin, $5 \mu \mathrm{g} / \mathrm{ml}$ leupeptin, and 5 $\mu \mathrm{g} / \mathrm{ml}$ pepstatin). Protein quantitation was determined by Bradford assay. Protein samples were resolved using $10 \%$ SDS-PAGE gels and transferred onto PVDF membrane overnight at $4^{\circ} \mathrm{C}$. Membranes were blocked in Tris Buffered Saline with 5\% milk and $0.1 \%$ Tween for 1 $\mathrm{h}$ at room temperature. Membranes were immunoblotted with the following primary antibodies diluted in Tris Buffered Saline with 5\% milk and 0.1\% Tween overnight at $4{ }^{\circ} \mathrm{C}$ : polyclonal anti-tubulin (Sigma), monoclonal anti-UHRF1 (BD Bioscience) followed by $1 \mathrm{~h}$ incubation at room temperature with the appropriate secondary antibody: anti-rabbit HRP-linked IgG or antimouse HRP-linked IgG (GE Healthcare). Protein detection was performed using the ECL Western blotting detection system (GE Healthcare) and exposed to scientific imaging film (Bioflex).

\section{Indirect Immunofluorescence and micronuclei analysis}

HeLa cells were seeded onto coverslips $\left(5 \times 10^{4} /\right.$ coverslip) pre-coated with $1 \%$ gelatin and $1 \%$ BSA. Following fixation in methanol/acetone and permeabilization with $0.4 \%$ Triton-X in PBS for 20 min, cells were blocked (1\% donkey serum/0.2\% Triton-X) for $20 \mathrm{~min}$ and then incubated overnight with either anti-histone $\mathrm{H} 3$ trimethylated on lysine 9 (anti-H3K9me3) or anti-histone $\mathrm{H} 4$ trimethylated on lysine 20 (anti-H4K20me3) overnight at $4^{\circ} \mathrm{C}$ (Millipore). Cells were then incubated with TRITC-conjugated secondary antibodies, counterstained with 4,6-diamidino-2-phenylindole (DAPI) and mounted with Vectashield (Vector laboratories). Images were acquired using an Imager.Z1 epifluorescence microscope and Axiovision software (Zeiss) following deconvolution. For micronuclei analysis, three UHRF1-depleted cell lines and three control cell lines were scored for the presence of micronuclei in triplicate, with each determination scoring $>200$ cells.

\section{Clonogenic assay}

Fixed amounts of cells exposed to varying doses of $\gamma$-irradiation (Nordion Gamma-cell, Ontario Cancer Institute) were seeded in $60 \mathrm{~mm}$ dishes in Dulbecco's Minimum Essential Media supplemented with 10\% fetal bovine serum (Invitrogen). Cells were left to form colonies for seven days. Colonies were fixed and stained with methylene blue in methanol. All survival curves were produced from an average \pm standard deviation of three to six determinations and are presented as a percent of control (non-irradiated) cells.

\section{Flow cytometry}

Cell-cycle analysis by bromodeoxyuridine (BrdU) and propidium iodide (PI) double staining was conducted essentially as described previously [22]. Cells $\left(5 \times 10^{5} /\right.$ $100 \mathrm{~mm}$ dish) exposed to 0,1 or $5 \mathrm{~Gy}$ were collected and fixed in $70 \%$ ethanol at $0,1,3,6,12$ or $24 \mathrm{~h}$ after exposure and stored at $-20^{\circ} \mathrm{C}$ prior to analysis. Measurement of $\gamma \mathrm{H} 2 \mathrm{AX}$ and PI double staining by flow cytometry was performed as described previously, but with the following modifications [22]. Cells were fixed in ice-cold $70 \%$ ethanol for $20 \mathrm{~min}$, rinsed in PBS and gently vortexed in PBS $+0.4 \%$ TritonX for $15 \mathrm{~min}$, then rinsed in PBS. Cells were then incubated with anti- $\gamma \mathrm{H} 2 \mathrm{AX}$ (1:200 of 05-636, Millipore) in the dark for $3 \mathrm{~h}$ at room temperature in $0.2 \%$ TritonX/1\% donkey serum. After 1 rinse in PBS, cells were then incubated in anti-mouse FITC (1:200, Jackson ImmunoResearch Labs) for $30 \mathrm{~min}$ at room temperature. After 1 rinse in PBS, cells were 
stained in PI $(50 \mu \mathrm{g} / \mathrm{ml}$ in PBS) for $30 \mathrm{~min}$ at room temperature, then analyzed by flow cytometry.

\section{Karyotype analysis}

FISH and its subsequent analysis were performed as described before [23]. Slides hydrated in PBS were fixed in $4 \% \mathrm{v} / \mathrm{v}$ formaldehyde: PBS, washed $3 \times 5 \mathrm{~min}$ in PBS, treated with $0.1 \mathrm{mg} / \mathrm{mL}$ pepsin (P-70000, Sigma) at $\mathrm{pH}$ 2 (3 min for fibroblasts, $11 / 2 \mathrm{~min}$ for lymphoblastoids), followed by repeated formaldehyde fixation and PBS washes before dehydration in an ethanol series $(70 \%$, $90 \%$ and $100 \%)$. Air-dried slides were first denatured at $80^{\circ} \mathrm{C}$ for $3 \mathrm{~min}$ with hybridization mixture containing deionized formamide (F9037; Sigma), $0.5 \mu \mathrm{g} / \mathrm{mL}$ Cy-3conjugated-(CCCTAA $)_{3}$ PNA probe complementary to telomeric sequence and $3 \mu \mathrm{g} / \mathrm{mL}$ Fluorescein isothiocyanate (FITC)-conjugated-centromic PNA probe (Applied Biosystems) in $10 \mathrm{mM}$ Tris ( $\mathrm{pH} \mathrm{7),} \mathrm{then} \mathrm{hybridized} \mathrm{in}$ the dark for $2 \mathrm{~h}$ at room temperature. Slides were then washed $2 \times 15 \mathrm{~min}$ in $70 \% \mathrm{v} / \mathrm{v}$ formamide (Merck)/1\% $\mathrm{w} / \mathrm{v} \mathrm{BSA} / 10 \mathrm{mM}$ Tris $(\mathrm{pH} 7.4)$ and $3 \times 5$ minute in 0.1 $\mathrm{M}$ Tris ( $1^{\text {st }}$ Base, Singapore)/0.15 M NaCl ( $\left.\mathrm{pH} 7.2\right) /$ $0.08 \% \mathrm{v} / \mathrm{v}$ Tween 20 (Sigma). Slides were dehydrated in an ethanol series, air-dried in the dark and counterstained with $0.0375 \mu \mathrm{g} / \mathrm{mL}$ DAPI in mounting media (Vectashield; Vector Laboratories). Images from approximately 50 metaphases were captured using an Axioplan 2 imaging fluorescent microscope (Zeiss) and analyzed for chromosomal aberrations such as breaks or fusions, which are indicative of genomic instability, with Isis Imaging Software (Metasystems, Germany).

\section{Results}

\section{Establishment of UHRF1-depleted cell lines}

To investigate the requirement of UHRF1 in genome integrity, we derived stable clones of HeLa cells expressing shRNA targeted to UHRF1. Three clones were selected that exhibited dramatically reduced UHRF1 expression, as demonstrated by Western analysis with anti-UHRF1 (Figure 1A). Cells expressing the first UHRF1 shRNA (UHRF1 shRNA cell line 1 and 2) or the second UHRF1 shRNA (cell line 3) showed a drastic depletion of UHRF1 protein levels compared to the three cell lines expressing control shRNA. Previous studies have demonstrated a role for UHRF1 in maintenance of heterochromatin organization and replication $[6,7,24]$. To examine the heterochromatin status in UHRF1-depleted cells, we immunostained UHRF1depleted and control cells with antibodies against heterochromatin markers H3K9me3 and H4K20me3. Control cell lines exhibited focal nuclear staining of H3K9me3 and H4K20me3 that superimposed DAPIdense regions of nuclear chromatin that represent heterochromatin (Figure 1B-D). In marked contrast,
UHRF1-depleted cells showed loss of focal H3K9me3 accumulation, with $\mathrm{H} 3 \mathrm{~K} 9 \mathrm{me} 3$ staining redistributed at the nuclear periphery (Figure 1C). The impact on H3K9me3 did not appear to reflect a generalized disruption of heterochromatin structure, as UHRF1-depleted cells displayed focal staining of H4K20me3 that was equivalent to that observed in control shRNA cell lines, although H4K20me3 appeared to be localized in larger focal regions than in control cells (Figure 1D). In both control and UHRF1-depleted lines, no fluctuation in either H3K9me3 or H4K20me3 staining was observed as a consequence of cell cycle position. Taken together, these findings demonstrate a significant reorganization of heterochromatin in cells depleted of UHRF1.

\section{Impact on proliferation and susceptibility to irradiation}

Previous studies have documented that depletion of UHRF1 results in proliferation arrest $[5,25]$. To assess whether reducing levels of UHRF1 would impact cell proliferation, we generated cell growth curves for UHRF1 depleted and control lines (Figure 2A). UHRF1depleted cells proliferated at a slightly slower rate than control cell lines, an effect that was only discernible following an extended ( $>1$ week) of analysis. Previous studies using murine embryonic stem cells with a targeted disruption of Uhrf1 and human cells with reduced UHRF1 have shown that these cells are more sensitive to $\gamma$-irradiation as analyzed by clonogenic assay [20,21]. To confirm these findings, two cell lines expressing UHRF1 shRNAs and two cell lines expressing control shRNAs were analyzed for sensitivity to $\gamma$-irradiation by clonogenic assay. As expected, cell lines depleted for UHRF1 exhibited hypersensitivity to $\gamma$-irradiation compared to control cell lines (Figure 2B).

\section{Cell cycle analysis following irradiation}

To monitor capacity for cell cycle arrest following DNA damage, we examined the percentage of cells at various stages of the cell cycle for one UHRF1 shRNA cell line and one control shRNA cell line following $\gamma$-irradiation. Cells were collected at various times after radiation (1 or $5 \mathrm{~Gy}$ ) for cell cycle analysis following staining with anti-BrdU and PI. In the absence of irradiation, UHRF1depleted cells showed a higher percentage of cells within the G1 phase fraction and a decrease in the $S$ phase fraction compared to control-depleted cells (Figure 3A and $3 \mathrm{~B}$ ). Following $1 \mathrm{~Gy}$ of irradiation, controls exhibited a transient arrest in cell cycle progression with an accumulation of cells in the G2/M fraction, a response typical of HeLa cells. For control cells, this transient arrest was maximal $12 \mathrm{~h}$ post-irradiation, with a nearly four-fold increase in cell accumulation in the G2/M fraction compared to non-irradiated cells (Figure 3A, C-E). In contrast, UHRF1-depleted cells showed a 


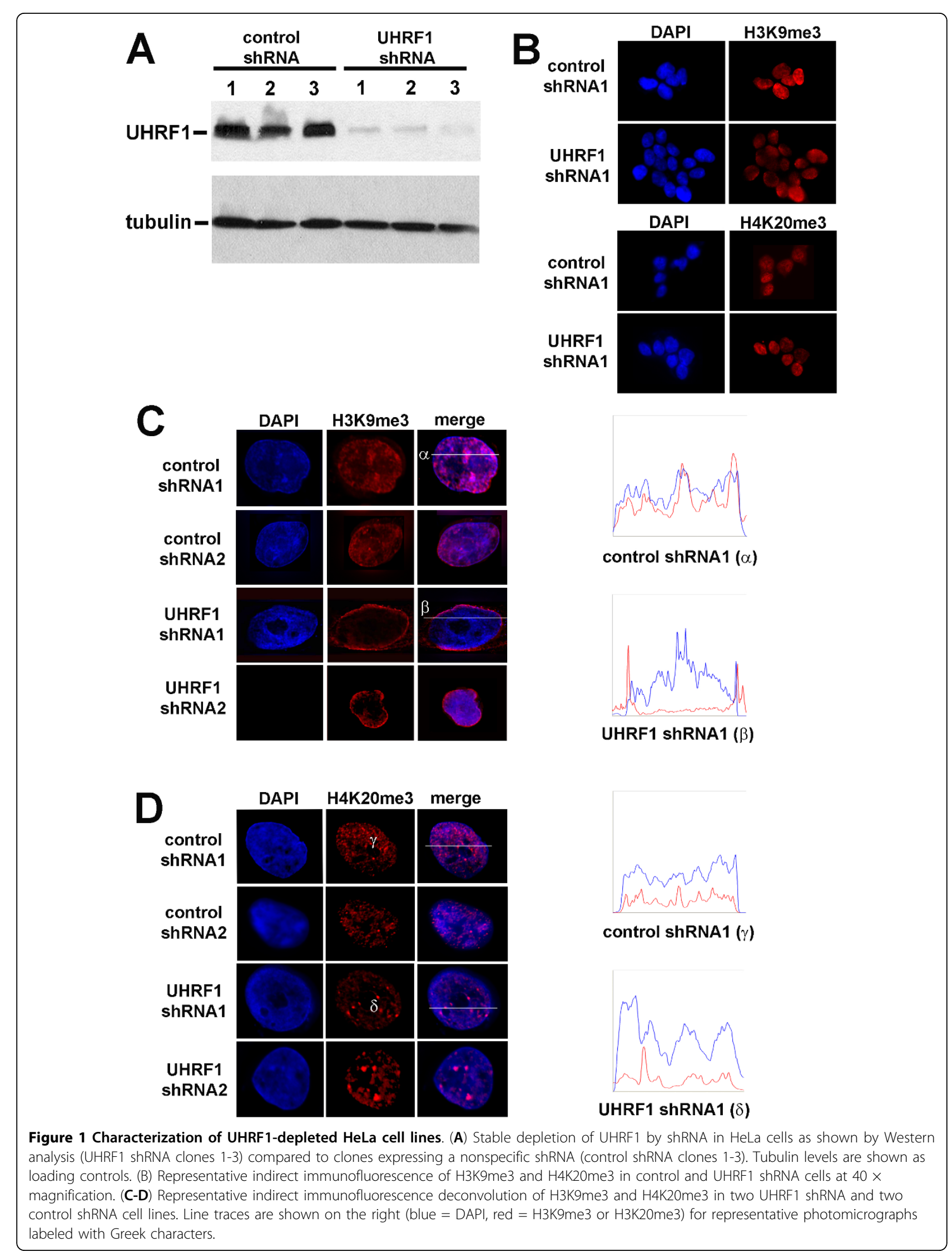



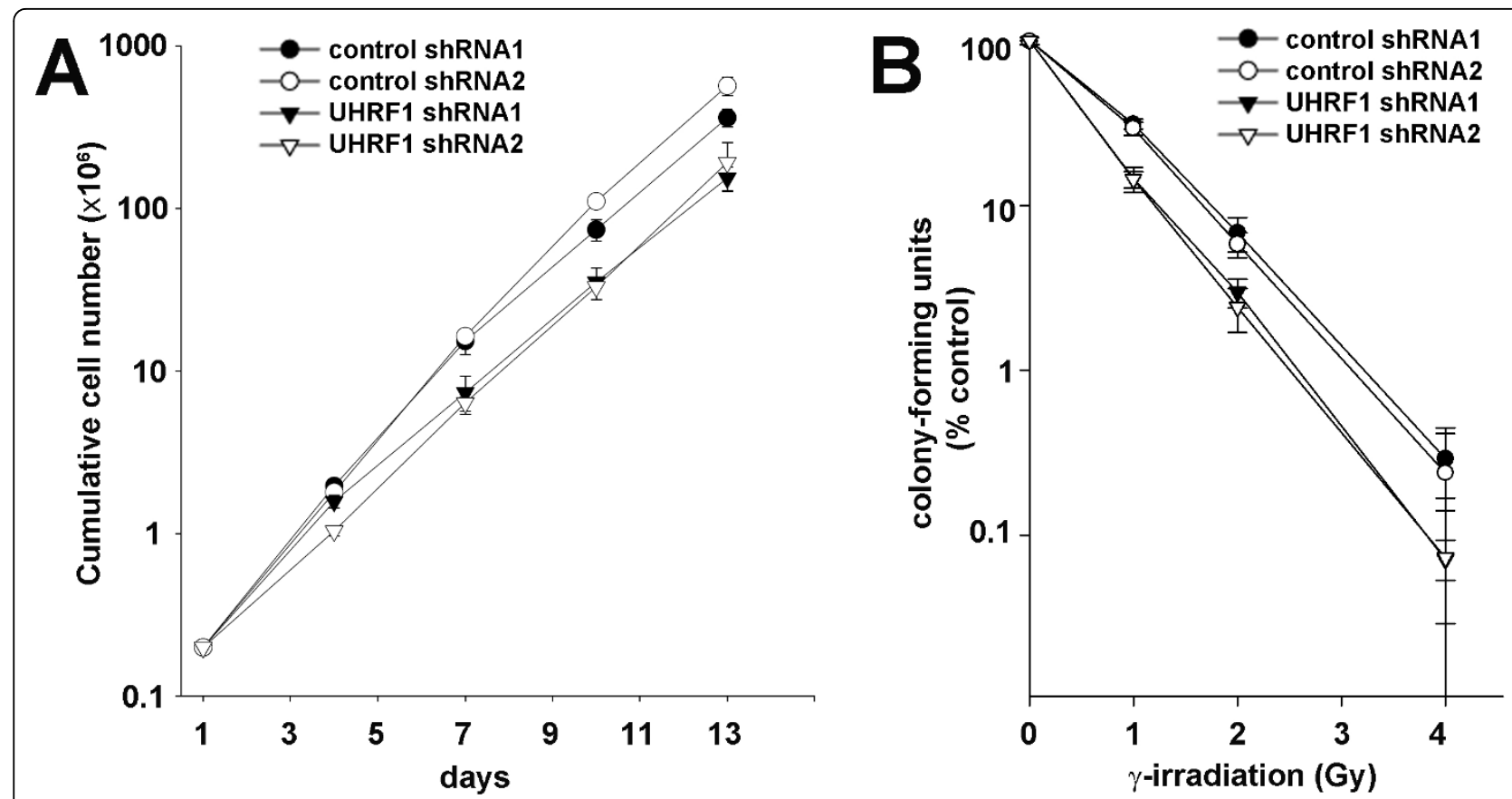

Figure 2 Impact of UHRF1 loss on proliferation and sensitivity to $\boldsymbol{\gamma}$-irradiation. (A) Cell growth curves of UHRF1-depleted and control cell lines. (B) Susceptibility of UHRF1-depleted cell lines to $\gamma$-irradiation. Cell lines were exposed to ionizing radiation and sensitivity was measured by colony formation.

decreased tendency to arrest following irradiation, with only a two-fold increase in the G2/M fraction and no noticeable decline in the $\mathrm{S}$ phase fraction $12 \mathrm{~h}$ after irradiation compared to non-irradiated cells. By $24 \mathrm{~h}$, cell cycle progression resumed for both UHRF1-depleted cells and controls. In contrast, the majority of cells irradiated with 5 Gy exhibited a more drastic arrest in cell cycle progression leading to a predominant accumulation of cells in the G2/M fraction, (Figure 3B). At $12 \mathrm{~h}$ following $5 \mathrm{~Gy}$, control cells accumulated in the G2/M fraction compared to earlier time points; howver, UHRF1-depleted cells showed a delayed accumulation in G2/M compared to controls (Figure 3B).

\section{$\gamma \mathrm{H} 2 \mathrm{AX}$ formation following $\gamma$-irradiation}

Phosphorylation of H2AX on serine $139(\gamma \mathrm{H} 2 \mathrm{AX})$ is an early event after introduction of DSBs [26]. To monitor the kinetics and extent of $\gamma \mathrm{H} 2 \mathrm{AX}$ following irradiation, we measured $\gamma \mathrm{H} 2 \mathrm{AX}$ content $0,1,3,6,12$ and $24 \mathrm{~h}$ in controls and UHRF1-depleted cells following $1 \mathrm{~Gy}$ or 5 Gy of $\gamma$-irradiation (Figure 4). Non-irradiated cells depleted of UHRF1 showed a nominally higher percentage of cells positive for $\gamma \mathrm{H} 2 \mathrm{AX}$ compared to control cells. Following 1 Gy of exposure, control cells showed a dramatic increase in the percentage of cells positive for $\gamma \mathrm{H} 2 \mathrm{AX}$ as expected, with maximal levels at $6 \mathrm{~h}$ that decreased to a level similar to non-irradiated cells by 24 h (Figure 4A). This time course of $\gamma \mathrm{H} 2 \mathrm{AX}$ induction corresponded to the degree of cell cycle arrest observed at 1 Gy (Figure 3A). Interestingly, the percentage of cells positive for $\gamma \mathrm{H} 2 \mathrm{AX}$ was markedly lower when UHRF1 was depleted compared to control cells. Following exposure to $5 \mathrm{~Gy}$ of irradiation, control cells showed a more drastic increase of $\gamma \mathrm{H} 2 \mathrm{AX}$-positive cells with maximal levels 1-6 h following irradiation. Again, UHRF1-depleted cells showed an attenuated increase in the percentage of $\gamma \mathrm{H} 2 \mathrm{AX}$-positive cells (Figure 4B). These findings were confirmed by detection of $\gamma \mathrm{H} 2 \mathrm{AX}$ by indirect immunofluorescence (Figure 4C). Taken together, these findings suggest that accumulation of $\gamma \mathrm{H} 2 \mathrm{AX}$ is defective in UHRF1-depleted cells following $\gamma$-irradiation.

\section{Micronuclei, centrosome copy number and karyotype}

Given the compromised DNA damage response in UHRF1-depleted cells, we sought to determine whether UHRF1 depletion conferred chromosomal instability. We stained three UHRF1-depleted and three control cell lines with DAPI and scored incidence of micronuclei (Figure 5A-D). Micronuclei are cytoplasmic chromosome fragments that fail to segregate properly during mitosis and are excluded from daughter nuclei at telophase $[27,28]$. Compared to the three control shRNA cell lines, UHRF1 shRNA cell lines exhibited a higher incidence of micronuclei (Figure $5 \mathrm{E}$ ). We sought to determine whether UHRF1 impacts centrosome status 


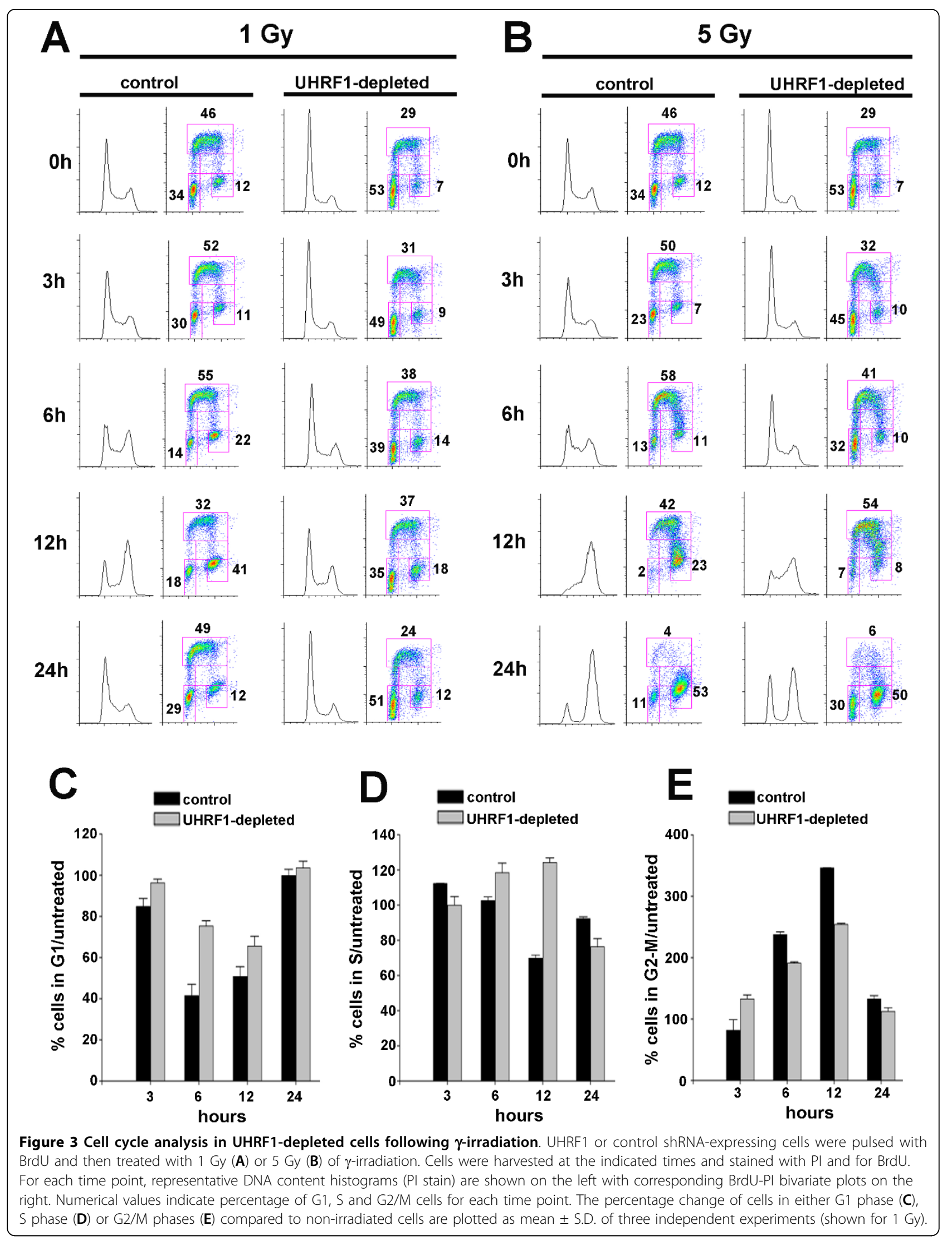




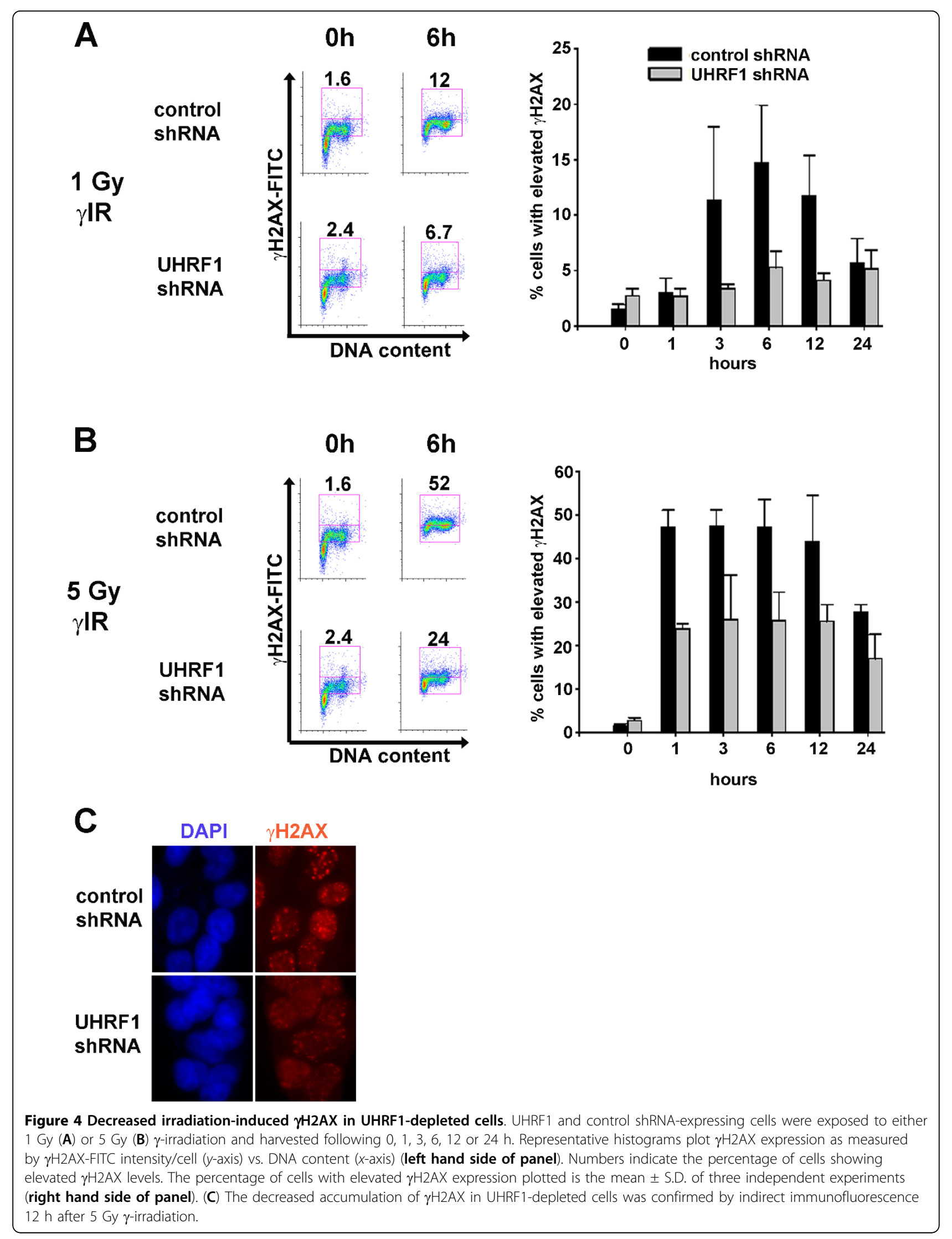



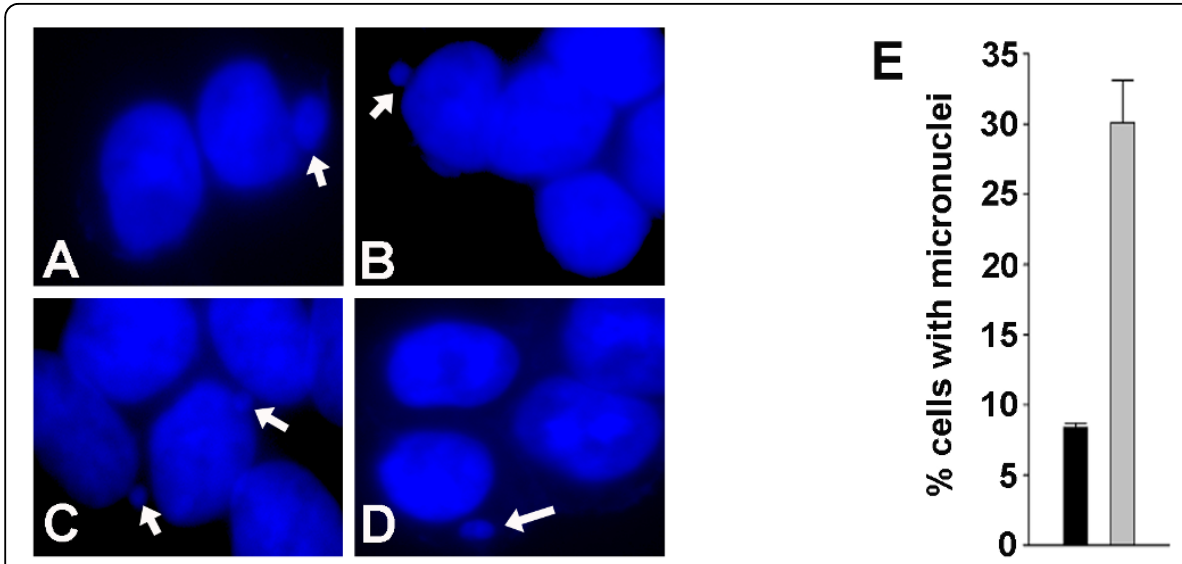

control shRNA UHRF1 shRNA
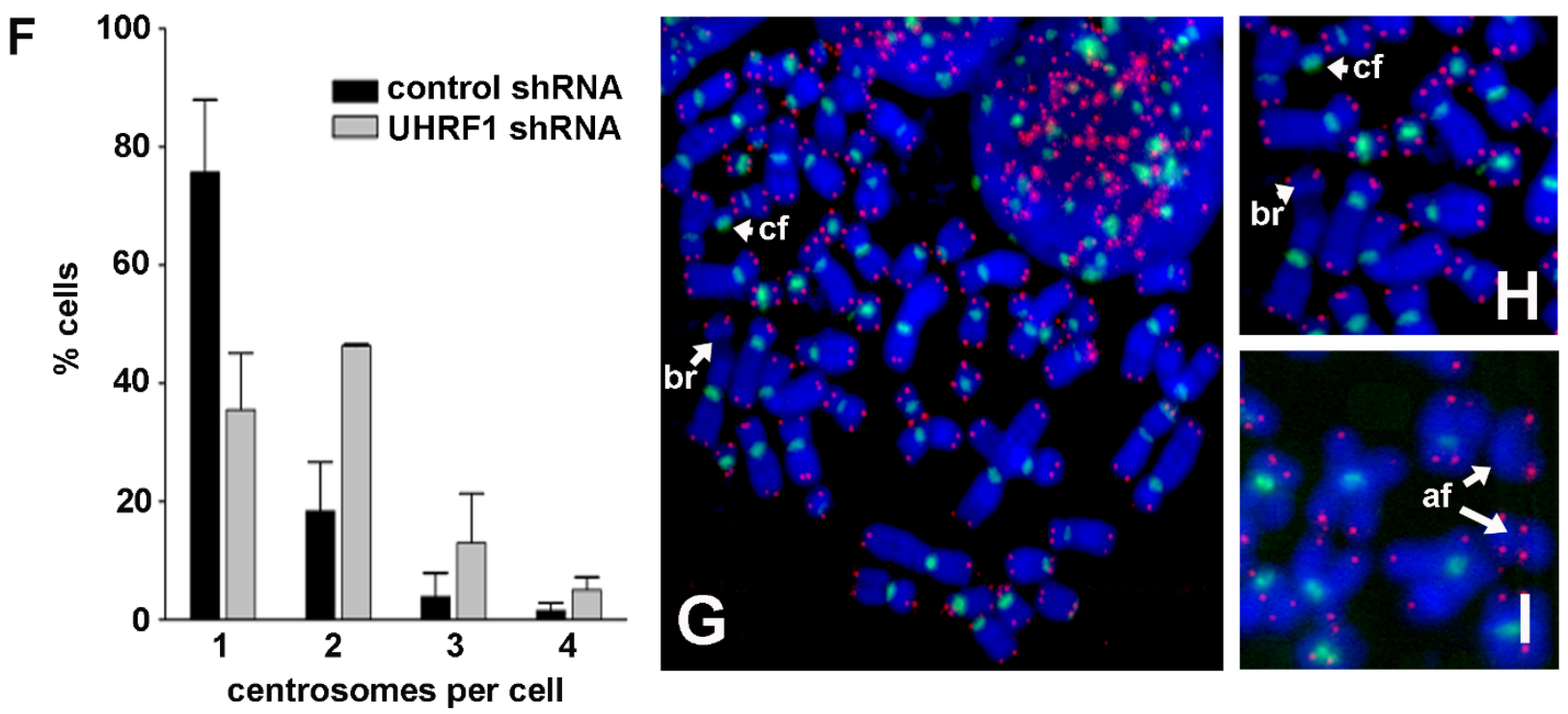

Figure 5 Chromosomal instability in UHRF1-depleted cells. (A-D) Representative photomicrographs showing presence of micronuclei in UHRF1-depleted cells. (E) Percentage of cells with micronuclei in control cells vs. UHRF1-depleted cells. Determinations from each cell line were performed in triplicate ( $n \geq 200$ cells/determination) and error bars represent standard deviations from the mean. (F) Percentage of control or UHRF1-depleted cells with 1, 2, 3, or 4 centrosomes per cell. (G-I) Representative images of DAPI-stained metaphases from UHRF1-depleted cells showing chromosomal aberrations (image shown in $\mathbf{H}$ is magnification of image in $\mathbf{G}$ ). br = chromosome break, cf = centrosomal fragment, af $=$ acentric fragments. Telomeres are visualized in red, centromeres in green.

in control and UHRF1-depleted cells. Examination of centrosome copy number following immunostaining with $\gamma$-tubulin revealed that the frequency of UHRF1depleted cells with 1 centrosome per cell was lower compared to control cells and the frequency of UHRF1depleted cells with 2 or more centrosomes per cells was higher compared to control cells (Figure 5F). To further assess alterations in chromosome integrity, we conducted karyotypic analyses on UHRF1-depleted and control cells. Visualization of telomeres and centromeres during karyotyping further clarified the scoring of aberrant metaphase chromosomes. Consistent with our observations of micronuclei and centrosomes, metaphase karyotypes of UHRF1-depleted cells showed a dramatic increase in the number of cells containing chromosome aberrations, particularly chromosome fragments (Figure 5G-I and Table 1).

\section{Discussion}

Using cell lines designed to permanently express reduced levels of UHRF1, we have demonstrated that UHRF1 is essential for maintaining the DNA damage response and genome integrity. Depletion of UHRF1 resulted in a greater propensity for cells to exhibit chromosomal instability, as shown by the increased frequency of micronuclei, supernumerary centrosomes and chromosome fragments in UHRF1-depleted cells. UHRF1 depleted cells exhibit increased susceptibility to 
Table 1 Increased chromosomal instability in UHRF1-depleted cells ${ }^{a}$.

\begin{tabular}{|c|c|c|c|c|c|}
\hline Cell line & Chromosome Breaks & Chromatid Breaks & Fusions & Fragments & Total No. of aberrations \\
\hline $\begin{array}{l}\text { Control } \\
\text { shRNA-1 }\end{array}$ & 0 & 0 & $\begin{array}{c}1 \\
(0.02 / \text { cell })\end{array}$ & $\begin{array}{c}8 \\
\text { (0.16/cell) }\end{array}$ & $\begin{array}{c}9 \\
\text { (0.18/cell) }\end{array}$ \\
\hline $\begin{array}{l}\text { Control } \\
\text { shRNA-2 }\end{array}$ & 0 & 0 & $\begin{array}{c}2 \\
(0.04 / \text { cell })\end{array}$ & $\begin{array}{c}12 \\
\text { (0.24/cell) }\end{array}$ & $\begin{array}{c}14 \\
\text { (0.28/cell) }\end{array}$ \\
\hline $\begin{array}{l}\text { Control } \\
\text { shRNA-3 }\end{array}$ & $\begin{array}{c}2 \\
(0.04 / \mathrm{cell})\end{array}$ & 0 & $\begin{array}{c}3 \\
(0.06 / \text { cell) }\end{array}$ & $\begin{array}{c}10 \\
\text { (0.2/cell) }\end{array}$ & $\begin{array}{c}15 \\
\text { (0.3/cell) }\end{array}$ \\
\hline $\begin{array}{l}\text { UHRF1 } \\
\text { ShRNA-1 }\end{array}$ & $\begin{array}{c}1 \\
\text { (0.02/cell) }\end{array}$ & 0 & $\begin{array}{c}5 \\
\text { (0.1/cell) }\end{array}$ & $\begin{array}{c}47 \\
\text { (0.94/cell) }\end{array}$ & $\begin{array}{c}53 \\
\text { (1.06/cell) }\end{array}$ \\
\hline $\begin{array}{l}\text { UHRF1 } \\
\text { ShRNA-2 }\end{array}$ & $\begin{array}{c}1 \\
(0.02 / \text { cell) }\end{array}$ & 0 & $\begin{array}{c}5 \\
\text { (0.1/cell) }\end{array}$ & $\begin{array}{c}51 \\
(1.02 / \text { cell) }\end{array}$ & $\begin{array}{c}57 \\
\text { (1.14/cell) }\end{array}$ \\
\hline $\begin{array}{l}\text { UHRF1 } \\
\text { ShRNA-3 }\end{array}$ & $\begin{array}{c}9 \\
\text { (0.18/cell) }\end{array}$ & $\begin{array}{c}1 \\
\text { (0.02/cell) }\end{array}$ & $\begin{array}{c}1 \\
\text { (0.02/cell) }\end{array}$ & $\begin{array}{c}54 \\
\text { (1.08/cell) }\end{array}$ & $\begin{array}{c}65 \\
\text { (1.3/cell) }\end{array}$ \\
\hline
\end{tabular}

${ }^{a}$ Results shown are number of chromosomal abnormalities detected in fifty metaphase spreads from three control shRNA and three UHRF1 shRNA (UHRF1depleted) cell lines. The frequency of a given abnormality/metaphase is shown below in parentheses.

DSB damage, compromised ability to undergo cell cycle arrest following DSB damage and decreased ability to accumulate $\gamma \mathrm{H} 2 \mathrm{AX}$.

Pericentric heterochromatin is the highly compacted chromatin surrounding the centromere, a region that is easily detected as DAPI-dense chromocenters in certain cell lines. Recent studies have demonstrated several important mechanisms whereby UHRF1 contributes to the maintenance of heterochromatin. DNA replication of heterochromatin presents several challenges, as the cell replicates not only DNA but also the spatial organization of compacted chromatin regions. Heterochromatin is characterized by hypermethylation of DNA and an increased accumulation in certain post-translational modifications to histones such as tri-methylation of histones $\mathrm{H} 3$ and $\mathrm{H} 4$ at lysines 9 and 20 respectively. UHRF1 is now considered to be a crucial component of the protein machinery that ensures heterochromatin epigenetic markers are recreated on newly replicated strands of DNA. UHRF1 plays an integral role in regenerating methylation of newly-replicated DNA by recruiting the DNA methyltransferase DMNT1 [10,11]. In addition, UHRF1 also binds to H3K9me3 which are highly represented in heterochromatin. Recent studies have reported conflicting results on the requirements of UHRF1 for maintaining H3K9me3 in heterochromatin. One report states that the heterochromatic distribution of H3K9me3 in cells with stable depletion of UHRF1 by shRNA was disrupted, with depleted cells showing diffuse $\mathrm{H} 3 \mathrm{~K} 9 \mathrm{me} 3$ staining compared to the focal heterochromatic enrichment in control cells [7]. Our observations confirm this finding, but contrast a subsequent study that does not report any significant changes in the redistribution of heterochromatin markers such as H3K9me3 in NIH 3T3 cells with UHRF1 transiently reduced by siRNA [24]. We suggest that the discrepancy may be due to experimental methodology employed, in that perhaps a transient reduction in UHRF1 levels will not impact heterochromatin histone marker modifications to the same extent as long term depletion of UHRF1.

We observed a slight impediment in the proliferation ability of UHRF1-depleted cells compared to control cell lines, in keeping with observations from previous studies $[5,9,17,25]$. The impact of loss of UHRF1 on proliferative capacity of cells appears to vary on the cell model used. UHRF1 depletion may impact $S$ phase progression due to a compromised ability to replicate heterochromatin or through reversal of repressed expression of factors that impede S phase entry, such as p21 [17]. Accordingly, the overall effects of UHRF1 on proliferation could vary in a cell-type dependent manner on the degree of heterochromatin compaction and distribution.

Our analysis of non-irradiated UHRF1-depleted cells revealed a decreased fraction of cells in $S$ phase with a corresponding increased fraction in G1 (not shown) compared to control cells. This decreased tendency for cells to be in $S$ phase in the absence of UHRF1 has been observed in prior studies $[5,9,25]$. A previous report observed that loss of UHRF1 led a small fraction of cells to be accumulated in G1 when challenged with doxorubicin, leading to the conclusion that loss of UHRF1 unmasked a G1 checkpoint response to DNA damage [4]. Although we see a similar increase in the G1 peak of cells exposed to irradiation, we attribute this to the cell cycle profile that the UHRF1-depleted cells demonstrate prior to irradiation, and not as the result of a novel checkpoint response to DNA damage.

Given the role of UHRF1 in maintenance of heterochromatin structure and our findings that loss of UHRF1 compromises chromosomal integrity, we propose that the genomic instability observed in UHRF1-depleted cells is likely due to disruption of heterochromatin structure, particularly the heterochromatin surrounding centromeres known as pericentric heterochromatin. Previous studies have determined that maintenance of the 
stringent pericentric heterochromatin structure is required to protect genomic stability $[29,30]$. In particular, loss of $\mathrm{H} 3 \mathrm{~K} 9 \mathrm{me} 3$ in this form of heterochromatin by the ablation of H3K9 methyltransferases Suv39h1 and Suv39h2 is sufficient to compromise chromosome segregation that could lead to the chromosomal aberrations seen in UHRF1-depleted cells [30].

A variety of studies have shown that loss of UHRF1 activity leads to the sensitization of cells to a variety of genotoxic agents including $\gamma$-irradiation, however the reason for this sensitivity has not been addressed $[20,21,25]$. Here we have demonstrated UHRF1-depleted cells exhibit an impaired ability to accumulate $\gamma \mathrm{H} 2 \mathrm{AX}$ following irradiation. Surprisingly, these cells show a reduced ability to generate $\gamma \mathrm{H} 2 \mathrm{AX}$, a hallmark signal of DSB repair despite the observation that loss of UHRF1 increases chromosomal instability and DSBs. Given the role of UHRF1 in heterochromatin maintenance and replication, our findings suggest that the chromatin modification properties of UHRF1 in heterochromatin are required for an optimal response to DSB damage caused by $\gamma$-irradiation. Approximately $10 \%$ of all nucleosomes in mammalian chromatin contain the histone $\mathrm{H} 2 \mathrm{~A}$ variant H2AX. Following the initiation of DSB damage by irradiation, the Mre11-Rad50-NBS1 (MRN) complex binds to free DNA ends and recruits PIK-family protein kinases such as ATM, ATR or DNA protein kinase that cause the initial phosphorylation of H2AX on serine 139 $(\gamma \mathrm{H} 2 \mathrm{AX})$. The recruitment of additional activated ATM to DSBs by the $\gamma \mathrm{H} 2 \mathrm{AX}$-binding protein MDC1 serves to propagate the signal and amplify the focal accumulation of $\gamma \mathrm{H} 2 \mathrm{AX}$, which then serves as a beacon for other DNA repair factors [reviewed in [31,32]].

Structural barriers of chromatin must be transiently removed during processing of DNA damage and restored following repair. Our findings of decreased $\gamma \mathrm{H} 2 \mathrm{AX}$ in UHRF1-depleted cells suggest that the disruption of heterochromatin associated with loss of UHRF1 compromises the accessibility of DNA damage response factors to process and repair DSBs. Reducing the degree of chromatin compaction through the reduction of histone $\mathrm{H} 1$ levels or inhibition of histone deacetylase activity has been demonstrated to increase the strength of the DNA damage response by increasing the extent of signaling generated per DNA lesion [33]. The focal phosphorylation of H2AX following $\gamma$-irradiation has been shown to occur less efficiently in heterochromatin compared to euchromatin, suggesting that changes in the packaging properties of chromatin have a marked impact on the strength of $\gamma \mathrm{H} 2 \mathrm{AX}$ signal generated in cells [34,35].

A recent study using an in vitro approach reported that UHRF1 can facilitate access of modifying enzymes to DNA encased in nucleosomal arrays [24]. We propose that UHRF1 may allow changes in heterochromatin structure that permit access of DNA surveillance and repair enzymes and that loss of this property may be responsible for the impaired DNA damage response observed in cells with reduced UHRF1. For example, our group and others show that stable reduction in UHRF1 does not change the total amount of H3K9me3 in cells but disrupts the focal heterochromatin enrichment of H3K9me3 normally observed in cells [7]. The methylation status of histone $\mathrm{H} 3$ on lysine 9 has not been reported to fluctuate in response to DNA damage, but serves as a binding scaffold for several heterochromatin proteins such as members of the HP1 family that have recently been implicated in the DNA damage response [36-38]. Release of $\mathrm{HP}-1 \beta$ bound to chromatin by disruption of its $\mathrm{H} 3 \mathrm{~K} 9 \mathrm{me}$-associated binding domain facilitates formation of $\gamma \mathrm{H} 2 \mathrm{AX}$ foci and loss of HP1- $\beta$ has been shown to result increased chromosomal instability $[36,39]$. In contrast, heterochromatin proteins HP1- $\alpha$, HP1- $\beta$, and HP1- $\gamma$ were shown to be recruited and accumulate at sites of DNA damage in a manner that is independent of H3K9me3 status [38]. Changes in heterochromatin modifications such as $\mathrm{H} 3 \mathrm{~K} 9 \mathrm{me} 3$ and HP1 binding distribution could impact other factors that bind to HP1 proteins such as KAP-1, a protein recently shown to facilitate the ATM-mediated repair of DSBs in heterochromatin $[37,40]$ or the histone acetyltransferase Tip60, which is activated by association with H3K9me3 [41]. Given that the extent and distribution of H3K9 methylation differs among cell lineages and is altered in human tumours, changes in methylation signatures of heterochromatin may contribute to the extent of genomic instability in tumour cells or to the therapeutic efficacy of antineoplastics by impacting the efficacy of DNA repair at specific chromatin regions in a cell-type specific manner $[42,43]$.

\section{List of Abbreviations}

DAPI: 4,6-diamidino-2-phenylindole; $\gamma \mathbf{H 2 A X}$ histone H2AX phosphorylated on serine 139; H3K9me3: tri-methylated lysine 9 of histone H3; H4K20me3: tri-methylated lysine 20 on histone H4; HP1: heterochromatin protein 1; UHRF1: Ubiquitinlike, containing PHD and RING finger domains, 1.

\section{Acknowledgements \\ This work was supported by operating grants from the Cancer Research Society Inc. and the Province of Ontario Ministry of Innovation Early Researcher Award to J.P.M., and by Defence Science and Technology Agency and National Medical Research Council, Singapore to M.P.H. H.M. is supported by a Canadian Institutes for Health Research Doctoral award and J.P.M. is a Canadian Institutes for Health Research New Investigator.}

\section{Author details}

${ }^{1}$ Department of Pharmacology and Toxicology, University of Toronto, Toronto, Ontario, M5 S 1A8, Canada. ²Department of Physiology, Yong Loo Lin School of Medicine, National University of Singapore, 117597, Singapore. 


\section{Authors' contributions}

HM generated the cell lines, performed the clonogenic assay and indirect immunofluorescence with DS LT performed the FACS analysis. HB and AG performed the Western analysis and assisted with the indirect immunofluorescence. DS performed the micronuclei and centrosome analysis. ML generated growth curve and assisted with the clonogenic assay. KG and MPH performed the karyotyping analysis. JPM conceived the study, participated in its design and coordination and wrote the manuscript. All authors read and approved the final manuscript.

\section{Competing interests}

The authors declare that they have no competing interests.

Received: 8 March 2010 Accepted: 8 June 2010 Published: 8 June 2010

\section{References}

1. Muto M, Utsuyama M, Horiguchi T, Kubo E, Sado T, Hirokawa K: The characterization of the monoclonal antibody Th-10a, specific for a nuclear protein appearing in the $S$ phase of the cell cycle in normal thymocytes and its upregulated expression in lymphoma cell lines. Cell Proliferation 1995, 28:645-657.

2. Fujimori A, Matsuda Y, Takemoto Y, Hashimoto Y, Kubo E, Araki R, Fukumura R, Mita K, Tatsumi K, Muto M: Cloning and mapping of NP95 gene which encodes a novel nuclear protein associated with cellular proliferation. Mamm Genome 1998, 9:1032-1035.

3. Uemura T, Kubo E, Kanaari Y, Ikemura T, Tatsumi K, Muto M: Temporal and spatial localization of novel nuclear protein NP95 in mitotic and meiotic cells. Cell Structure and Function 2000, 25:149-159.

4. Arima Y, Hirota T, Bronner C, Mousli M, Fujiwara T, Niwa S-i, Ishikawa H, Saya H: Down-regulation of nuclear protein ICBP90 by p53/p21dependent DNA-damage checkpoint signals contributes to cell cycle arrest at G1/S transition. Genes to Cells 2004, 9:131-142.

5. Bonapace IM, Latella L, Papait R, Nicassio F, Sacco A, Muto M, Crescenzi M, Di Fiore PP: Np95 is regulated by E1A during mitotic reactivation of terminally differentiated cells and is essential for S phase entry. J Cell Biol 2002, 157:909-914.

6. Papait R, Pistore C, Negri D, Pecoraro D, Cantarini L, Bonapace IM: Np95 is implicated in pericentromeric Heterochromatin replication and in major satellite silencing. Mol Biol Cell 2007, 18:1098-1106.

7. Karagianni P, Amazit L, Qin J, Wong J: ICBP90, a novel methyl K9 H3 binding protein linking protein ubiquitination with heterochromatin formation. Mol Cell Biol 2008, 28:705-717.

8. Citterio E, Papait R, Nicassio F, Vecchi M, Gomiero P, Mantovani R, Di Fiore PP, Bonapace IM: Np95 is a histone-binding protein endowed with ubiquitin ligase activity. Mol Cell Biol 2004, 24:2526-2535.

9. Unoki M, Nishidate T, Nakamura Y: ICBP90, an E2F-1 target, recruits $\mathrm{HDAC} 1$ and binds to methyl- $\mathrm{CpG}$ through its SRA domain. Oncogene 2004, 23:7601-7610.

10. Bostick M, Kim JK, Esteve P-O, Clark A, Pradham S, Jacobsen SE: UHFR1 plays a role in maintaining DNA methylation in mammalian cells. Science 2007, 317:1760-1764

11. Sharif J, Muto M, Takebayashi S-I, Suetake I, Iwamatsu A, Endo TA, Shinga J, Mizutani-Koseki Y, Toyoda T, Okamura K, Tajima S, Mitsuya K, Okano M, Koseki H: The SRA protein Np95 mediates epigenetic inheritance by recruiting Dnmt1 to methylated DNA. Nature 2007, 450:908-912.

12. Arita $K$, Ariyoshi M, Tochio H, Nakamura Y, Shirakawa M: Recognition of hemi-methylated DNA by the SRA protein UHRF1 by a base-flipping mechanism. Nature 2008, 455:818-821.

13. Avvakumov GV, Walker JR, Xue S, Li Y, Duan S, Bronner C, Arrowsmith CH, Dhe-Paganon S: Structural basis for recognition of hemi-methylated DNA by the SRA domains of human UHRF1. Nature 2008, 455:822-825.

14. Qian C, Li S, Jakonic J, Zeng L, Walsh MJ, Zhou MM: Structure and hemimethylated $\mathrm{CpG}$ binding of the SRA domain from human UHRF1. J Biol Chem 2008, 283:34490-34494.

15. Rottach A, Frauer C, Pichler G, Bonapace IM, Spada F, Leonhardt H: The multi-domain protein Np95 connects DNA methylation and histone modification. Nucl Acids Res 2010, 38(6):1796-804.

16. Achour $\mathrm{M}$, Jaca $\mathrm{X}$, Ronde $\mathrm{P}$, Alhosin $\mathrm{M}$, Charlot $\mathrm{C}$, Jeanblanc $\mathrm{M}$, Macaluso $\mathrm{M}$, Giordano A, Hughes AD, Schini-Kerth VB, Bronner C: The interaction of the
SRA domain of ICBP90 with a novel domain of DNMT1 is involved in the regulation of VEGF gene expression. Oncogene 2008, 27:2187-2197.

17. Kim JK, Esteve PO, Jacobsen SE, Pradham S: Uhrf1 binds G9a and participates in p21 transcriptional regulation in mammalian cells. Nucl Acids Res 2008, 37:493-505.

18. Meilenger $D$, Fellinger $K$, Bultmann S, Rothbauer U, Bonapace IM, Klinkert WEF, Spada F, Leonhardt H: Np95 interacts with de novo DNA methyltransferases, Dnmt3a and Dnmt3b, and mediates epigenetic silencing of the viral CMV promoter in embryonic stem cells. EMBO reports 2009, 10:1259-1264.

19. Jin W, Liu Y, Xu Sg, Win Wj, Li Jj, Yang Jm, Shao ZM: UHRF1 inhibits MDR1 gene transcription and sensitizes breast cancer cells to anticancer drugs. Breast Cancer Res Treat 2009, DOI: 10.1007/s10549-009-0683-8.

20. Muto M, Kanari Y, Kubo E, Takabe T, Kurihara T, Fujimori A, Tatsumi K: Targeted disruption of Np95 gene renders murine embryonic stem cells hypersensitive to DNA damaging agents and DNA replication blocks. J Biol Chem 2002, 277:34549-34555.

21. Muto M, Fujimori A, Nenoi M, Daino K, Matsuda Y, Kuroiwa A, Kubo E, Kanari Y, Utsuno M, Tsuji H, Ukai H, Mita K, Takahagi M, Tatsumi K: Isolation and characterization of a novel human radiosusceptibility gene, NP95. Radiation Research 2006, 723-733.

22. Tamblyn L, Li E, Sarras H, Srikanth P, Hande MP, McPherson JP: A role for Mus81 in the repair of chromium-induced DNA damage. Mutation Research 2009, 660:57-65.

23. Hande MP, Samper E, Landsdorp P, Blasco MA: Telomere length dynamics and chromosomal instability in cells derived from telomerase-null mice. J Cell Biol 1999, 144:589-601.

24. Papait R, Pistore C, Grazini U, Babbio F, Cogliati S, Pecoraro D, Brino L, Morand AL, Dechampesme AM, Spada F, Leonhardt H, McBlane F, Oudet P, Bonapace IM: The PHD domain of Np95 (mUHRF1) is involved in largescale reorganization of pericentromeric heterochromatin. Molecular Biology of the Cell 2008, 19:3554-3563.

25. Jenkins $Y$, Markovtsov V, Lang W, Sharma P, Pearsall D, Warner J, Franci $C$, Huang B, Huang J, Yam GC, Vistan JP, Pali E, Vialard J, Janicot M, Lorens JB, Payan DG, Hitoshi Y: Critical role of the ubiquitin ligase activity of UHFR1, a nuclear RING finger protein, in tumour cell growth. Mol Biol Cell 2005, 16:5621-5629.

26. Paull TT, Rogakou EP, Yamazaki V, Kirchgessner CU, Gellert M, Bonner WM: A critical role for histone $\mathrm{H} 2 \mathrm{AX}$ in recruitment of repair factors to nuclear foci after DNA damage. Current Biology 2000, 10:886-895.

27. Therman E, Susman M: Human Chromosomes, Structure, Behaviour and Effects. New York, NY: Springer-Verlag 1993.

28. Hoffelder DR, Luo L, Burke NA, Watkins SC, Gollin SM, Saunders WS: Resolution of anaphase bridges in cancer cells. Chromosoma 2004, 112:389-397.

29. Taddei A, Maison C, Roche D, Almouzni G: Reversible disruption of pericentric heterochromatin and centromere function by inhibiting deacetylases. Nature Cell Biol 2001, 3:114-120.

30. Peters AHFM, O'Carroll D, Scherthan H, Mechtler K, Sauer S, Schofer C, Weipoltshammer K, Pagani M, Lachner M, Kohlmaier A, Opravil S, Doyle M, Sibilia M, Jenuwein T: Loss of the Suv39 $\mathrm{h}$ histone methyltransferases impairs mammalian heterochromatin and genome stability. Cell 2001, 107:323-337.

31. Harper JW, Elledge SJ: The DNA damage response: ten years after. Mol Cell 2007, 28:739-745.

32. Dery U, Masson JY: Twists and turns in the function of DNA damage signaling and repair proteins by post-translational modifications. DNA Repair 2007, 6:561-577.

33. Murga M, Jaco I, Fan Y, Soria R, Martinez-Pastor B, Cuadrado M, Yang SM, Blasco MA, Skoultchi Al, Fernandez-Capetillo O: Global chromatin compaction limits the strength of the DNA damage response. I Cell Biol 2007, 178:1101-1108.

34. Karagiannis TC, KN H, El-Osta A: Disparity of histone deacetylase inhibition on repair of radiation-induced DNA damage on euchromatin and constitutive heterochromatin compartments. Oncogene 2007, 26:3963-3971.

35. Cowell IG, Sunter NJ, Singh PB, Austin CA, Durkacz BW, Tilby MJ: Gamma $\mathrm{H} 2 \mathrm{AX}$ foci form preferentially in euchromatin after ionizing radiation. PLOS ONE 2007, 2:e1057. 
36. Ayoub N, Jeyasekharan AD, Bernal JA, Venkitaraman AR: HP1-beta mobilization promotes chromatin changes that initiate the DNA damage response. Nature 2008, 453:682-686.

37. Goodarzi AA, Noon AT, Deckbar D, Ziv Y, Shiloh Y, Lobrich M, Jeggo PA: ATM signaling facilitates repair of DNA double-strand breaks associated with heterochromatin. Mol Cell 2008, 31:167-177.

38. Luijsterburg MS, Dinant C, Lans H, Stap J, Wiernasz E, Lagerwerf S, Warmerdam DO, Lindh M, Brink MC, Dobrucki JW, Aten JA, Fousteri MI, Jansen G, Dantuma NP, Vermeulen W, Mullenders LHF, Houtsmuller AB, Verschure PJ, van Driel R: Heterochromatin protein 1 is recruited to various types of DNA damage. J Cell Biol 2009, 185:577-586.

39. Aucott R, Bullwinkel J, Yu Y, Shi W, Billur M, Brown JP, Menzel U, Kioussis D, Wang G, Reisert I, Weimer J, Pandita RK, Sharma GG, Pandita TK, Fundele R, Singh PB: HP1-beta is required for development of the cerebral neocortex and neuromuscular junctions. J Cell Biol 2008, 183:597-606.

40. Ziv Y, Bielopolski D, Galanty Y, Lukas C, Taya Y, Schultz DC, Lukas J, BekkerJensen S, Bartek J, Shiloh Y: Chromatin relaxation in response to DNA double-strand breaks is modulated by a novel ATM- and KAP-1 dependent pathway. Nature Cell Biol 2006, 8:870-876.

41. Sun $Y$, Jiang $X, X u Y$, Ayrapetov MK, Moreau LA, Whetstine JR, Price BD: Histone $\mathrm{H} 3$ methylation links DNA damage detection to activation of the tumour suppressor Tip60. Nature Cell Biol 2009, 11:1376-1382.

42. Bernstein BE, Meissner A, Lander ES: The mammalian epigenome. Cell 2007, 128:669-681

43. Seligson DB, Horvath S, McBrian MA, Mah V, Yu H, Tze S, Wang Q, Chia D, Goodglick L, Kurdistani SK: Global levels of histone modifications predict prognosis in different cancers. American Journal of Pathology 2009, 174:1619-1628.

doi:10.1186/2041-9414-1-7

Cite this article as: Mistry et al:: UHRF1 is a genome caretaker that facilitates the DNA damage response to $\gamma$-irradiation. Genome Integrity $20101: 7$.

\section{Submit your next manuscript to BioMed Central} and take full advantage of:

- Convenient online submission

- Thorough peer review

- No space constraints or color figure charges

- Immediate publication on acceptance

- Inclusion in PubMed, CAS, Scopus and Google Scholar

- Research which is freely available for redistribution

Submit your manuscript at www.biomedcentral.com/submit
C Biomed Central 